Contents list available at IJRED website

Int. Journal of Renewable Energy Development (IJRED)

Journal homepage: www.ijred.com

\title{
Analytical Investigations of Kinetic and Heat Transfer in Slow Pyrolysis of a Biomass Particle
}

\author{
S. J. Ojolo ${ }^{\mathrm{a}}{ }^{*}$ C. A. Oshekub and M.G. Sobamowo ${ }^{\mathrm{a}}$ \\ aDepartment of Mechanical Engineering, University of Lagos, Akoka, Lagos, NIGERIA. \\ ${ }^{b}$ Centre for Space Transport and Propulsion, National Space Research and Development Agency, \\ Federal Ministry of Science and Technology, FCT, Abuja, NIGERIA.
}

\section{Article history:}

Received March 02, 2013

Received in revised form April 15, 2013 Accepted May 01, 2013 Available online

\begin{abstract}
The utilization of biomass for heat and power generation has aroused the interest of most researchers especially those of energy .In converting solid fuel to a usable form of energy, pyrolysis plays an integral role. Understanding this very important phenomenon in the thermochemical conversion processes and representing it with appropriate mathematical models is vital in the design of pyrolysis reactors and biomass gasifiers. Therefore, this study presents analytical solutions to the kinetic and the heat transfer equations that describe the slow pyrolysis of a biomass particle. The effects of Biot number, temperature and residence time on biomass particle decomposition were studied. The results from the proposed analytical models are in good agreement with the reported experimental results. The developed analytical solutions to the heat transfer equations which have been stated to be "analytically involved" showed average percentage error and standard deviations 0.439 and 0.103 from the experimental results respectively as compared with previous model in literature which gives average percentage error and standard deviations 0.75 and 0.106 from the experimental results respectively. This work is of great importance in the design of some pyrolysis reactors/units and in the optimal design of the biomass gasifiers.
\end{abstract}

Keywords: analytical solutions; biomass particle; energy; heat transfer; kinetics, pyrolysis

\section{Introduction}

The World population has increased at an explosive rate from 1.65 billion in the $20^{\text {th }}$ century to just over 7 billion in the $21^{\text {st }}$ century and continues to increase at an alarming rate. Consequently, the ever increasing population increases in energy demands, dwindles sources of fossil fuels, increases pollution levels in the environment and continuously contributes to global warming. Tapping the energy available from the renewable resources allows the attainment of notable reductions in the adverse effects from the utilization of fossil fuels to meet the present energy demands. On meeting the world energy demands in a renewable way, thermochemical conversion of biomass (pyrolysis, gasification, combustion) is one of the most promising non-nuclear forms of future energy (Babu \& Sheth 2006). According to the studies by the Shell
International Petroleum Company and the intergovernmental Panel on Climate Change (2001), biomass could satisfy between one-quarter and to about one-half of the world's energy demand by the middle of the $21^{\text {st }}$ century. International Energy Agency, World energy Outlook (2012) reported that the consumption of biomass for power generation) and biofuels will grows four-fold by 2035, with increasing volumes being traded internationally. The reported also added that the Global bioenergy resources are more than sufficient to meet the projected biofuels and biomass supply without competing with food production. Therfore, its availability strongly attests to its capability to provide and sustain the world's energy demand for economic growth and development. Also, the various advantages of biomass gasification technology, such as highly efficient process, flexibility in applications over a range of output, low initial investment, notable reduction in

*Corresponding Author:

Email: ojolosunday@yahoo.com 
environmental pollution and global warming, low cost of power production, better process control and convenience, cleaner combustion in connected equipment, low maintenance cost have aroused the interests of many researchers to solving the world energy problems through biomass gasification. Moreover, most practical combustor systems such as boilers, gas turbine, diesel engines, rockets etc use liquid and solid fuels as the energy source. Although gaseous and liquid fuels are simple and clean to use, their resources are limited, thus, solid fuels are finding increasing use in electric power generation. This in addition to the previously cited advantages has also aroused the interests of various researchers in the field of solid fuel combustions. A detail understanding of what happen to solid fuel/biomass particles in the reacting medium calls for good knowledge of the integral processes in the conversion of the solid fuel to usable energy form. One of these processes is pyrolysis which involves the thermal degradation/decomposition of biomass feedstock in the absence of oxygen/air, to form charcoal, tar and gaseous products.

In fixed/moving bed gasifier, the packed bed consists of particles of a large variety of sizes, typically between 5 and $25 \mathrm{~mm}$ for automatic furnaces (Bruch 2003). During the thermal conversion of biomass, different processes such as drying, pyrolysis and char conversion, occur which may overlap to some extent within a particle depending, e.g. on fuel type, particle size or heating rate. Focusing on the pyrolysis as an integral process in the thermochemical conversion of biomass, the overall process of pyrolysis appears simple but the sequence of reactions is complex and involves both endothermic and exothermic processes whose thermodynamics and kinetics are poorly understood (Pyle and Zaror 1984). Also, Babu and Chaurasia (2004) pointed out that In spite of these many advantages, little work has been reported in the literature on the mechanistic modeling of such kinetics. They further added that this may be attributed to the extreme complexity of the pyrolysis process due to the presence of homogeneous and heterogeneous reactions occurring consecutively along with heat, mass and momentum transfer operations occurring simultaneously during the process. Under such complex phenomena, it is impossible to formulate a complete mathematical model of pyrolysis which will still be mathematically tractable. As a compromise between mathematical tractability and accuracy of description, simplified models are employed under certain defined conditions to predict the conversion process of biomass single particle. In fact, the need for the simple rationally-based models of pyrolysis as a basis for reactor design has been identified in the survey of low temperature (i.e less than $600^{\circ} \mathrm{C}$ ) pyrolytic conversion of biomass to usable forms of energy since the complications involved in the numerical solution of a more sophisticated models make them unsuitable for design and prediction purposes (Pyle and Zaror 1984). One angle of approach had been adopted to develop simple and economic models which aggregate the more important aspects of the sequence of events as a solid sample is pyrolysed.

The heat conduction equations in a pyrolysizing solid fuel such as wood were first combined with those for heat generation by Bamford et al. (1946), assuming a first order single step reaction. The model developed by Bamford has been used by various researchers (Robert and Clough, 1963; Tinney 1965). The effects of internal convection and variable transport properties were later incorporated by Matsumoto et al. (1969) and Kung (1972). The effect of char formation was considered by Kung (1972), and the rate of char removal by oxidation was modelled by Matsumoto et al. (1969). Temperature-dependent property variation was also studied by Matsumoto et al. (1969), Kung (1972), Maa and Bailie (1973), Kansa et al. (1977), Chan et al. 1985). Multi-step reaction schemes have been presented by Tinney (1965), Kung (1972), Chan et al. (1985) and Koufopanos et al. (1991). The heat of reaction of pyrolysis have been modelled by Lee et al. (1976), while the effect of anisotropy of the pyrolysing medium has been considered by Kansa et al. (1977). Miyanamie (1977) studied the effects of heat of reaction and Lewis number on the pyrolysis of solid particle. For the motion of the gases within the solid, a momentum equation was included (Kansa et al. 1977). Fan et al. (1977) developed a 'volume reaction' model taking into account simultaneous heat and mass transfer in the particle. Pyle and Zaror (1984) experimentally investigated the pyrolysis of biomass. Simmons and Gentry (1986) analysed a simplified heat transfer model with an assumed first order reaction for the estimation of an upper bound for biomass particle size in conducting experimental pyrolysis kinetic. Villermaux et al. (1986) presented a Volatilization Thermal Penetration model (VTP) for any kind of solid reaction where volatilization is controlled by heat conduction from the outer surface. On the modeling of pyrolysis of biomass particle, particularly on the studies of the kinetic, thermal and heat transfer effects, Koufopanos et al. (1991) assumed the pyrolysis process to be primary and secondary kinetic reactions. Di Blasi (1993) analysed the effects of convection and secondary reactions within porous solid fuels undergoing pyrolysis. Melaaen and Gronli (1997) presented models on moist wood drying andpyrolysis. Jalan and Srivastava (1999) explored kinetic and heat transfer effects on the pyrolysis of a single biomass cylindrical pellet. Ravi (2003) proposed a semi-emperical model for pyrolysis of sawdust in an annular packed bed using pseudo-first order reaction for the chemical reaction of the pyrolysis. In their model, Babu and Chaurasia (2004) considered time-dependent density and temperature-dependent specific heat capacity of biomass to investigate the dominant design variables in pyrolysis of biomass particles of different geometries in 
a thermally thick regime. In the recent time, Sheth and Babu (2006), presented Kinetic Model for biomass pyrolysis and concluded that Pyrolysis in wood is typically initiated at $200^{\circ} \mathrm{C}$ and lasts till $450-500^{\circ} \mathrm{C}$, depending on the species of wood. Yang et al. (2006) presented that the major stage of biomass pyrolysis occurs between $250-450^{\circ} \mathrm{C}$. Mandl et al. (2009), pointed out in their work that the pyrolysis of softwood pellets takes place at around $425 \mathrm{~K}$ and char particles and volatiles are formed while Weerachanchai et al. (2010) submitted that the major decomposition of all biomasses occurred in the range of $250-400^{\circ} \mathrm{C}$. Katarzyna et al. (2011), in their studies of poplar wood, concluded that the decomposition of hemicelluloses and cellulose take place in active pyrolysis in the temperature from 473-653K and 523-623K, respectively. They then added that Lignin decomposes in both stages: active and passive pyrolysis in the range from 453-1173K without characteristics peaks.

In providing solutions to the kinetic and heat conduction equations in pyrolyzing solids in most published literature, recourse had been made to numerical methods (approximation methods) because of the non-linear nature of the developed models. Moreover, the analytical solutions (exact/closed form solutions) of these equations have been stated to be 'involved' (Zaror, 1982). Therefore, this study presented analytical solutions of pyrolysis of biomass particle. Simulations were carried out to investigate temperature history and profiles, kinetic, convective and radiative heat transfer on the pyrolysis of biomass particle. Owing to the better predictions of the analytical results than the numerically predicted results as compared to experimental data, these presented model solutions will be very useful in the design of industrial pyrolysis units.

\section{The Theorectical Background}

Heat is transferred to the biomass particle surface from gaseous surrounding by conduction, radiation and/ or convection and then to the interior of the particle mainly by conduction. The temperature inside the particles increases as the heat penetrates more into the interiors of the solid causing moisture evaporation i.e. drying off the moisture. The rate of drying depends upon the temperature, velocity, and moisture content of the drying gas, as well as the external surface area of the feed material, the internal diffusivity of moisture and the nature of bonding of moisture to that material, and the radiative heat transfer. As the temperature increases, biomass particle decomposes into charcoal, tar and gaseous products. The amounts of each of these products vary depending on the zone temperature, rate of heating, structure, and composition and size of catalysts. At the higher temperatures, rate of thermal decomposition or pyrolysis is not only controlled by heat transfer, but also influenced by heat of reaction, bed or particle shape/length, air flow rate, initial moisture content of solid fuel.

\section{The Model Assumptions}

The basic assumptions of this model are:

1. The properties of the solid are constants and independent of temperature.

2. The heat transfer takes place by conduction within the solid and that heat can be locally produced (or consumed) by pyrolysis. Also, thermal conductivity and heat capacity are constant.

3. The rate of volatilization of the solid fuel increases with temperature according to Arrhenius law.

4. The reactions rate is of the first-order and the reaction is endothermic and it includes both primary and secondary pyrolysis processes.

5. The volatiles leave the solid as soon as they are formed. The heat transfer analysis is limited to primary pyrolysis.

6. One-dimensionality assumption for the heat within the solid is assumed.

7. The biomass was totally converted to gases, char and tar.

8. There is no temperature gradient at the centre line (at $\mathrm{r}=0$ ) of the solid particle i.e. $\left(\frac{\partial T}{\partial r}\right)_{r=0}=0$

\section{Model Formulation}

The kinetic scheme as shown in Fig.1 describes the process of pyrolysis (primary and secondary) which involves thermal decomposition of biomass into gases, tar (liquid product of biomass pyrolysis, known as biooil or pyrolysis oil) and char, and the tar further decompose into char and gases.

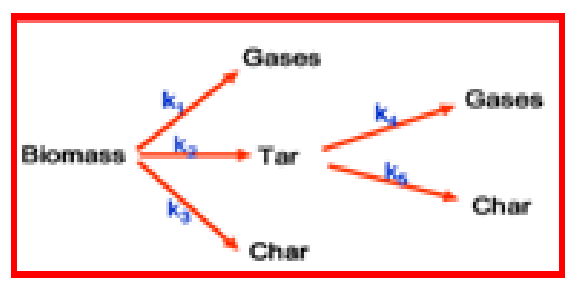

Fig. 1 Two-stage parallel reaction model of biomass pyrolysis

This two-stage parallel reaction model of biomass pyrolysis has previously been used by other researchers (Shafizadeh and Chin, 1977; Thurner and Mann 1981; Chan et al. 1985; Font et al. 1990, Di Blasi 1994; Janse et al. 2000; Yang et al. 2007)

The kinetic equations of pyrolysis, the heat transfer model and the corresponding initial and boundary conditions are given as: 
$\frac{\partial C_{B}}{\partial t}=-\left(k_{1}+k_{2}+k_{3}\right) C_{B}$

$\frac{\partial C_{T}}{\partial t}=k_{2} C_{B}-\varepsilon\left(k_{4}+k_{5}\right) C_{T}$

$\frac{\partial C_{C}}{\partial t}=k_{3} C_{B}+\varepsilon k_{5} C_{T}$

$\frac{\partial C_{G}}{\partial t}=k_{1} C_{B}+\varepsilon k_{4} C_{T}$

where,

$k_{i}=A_{i} \exp \left[\left(\frac{-E_{i}}{R T}\right)\right] \quad i=1-5$

and the subscripts B, T, C, and G represent Biomass, Tar, Char and Gas repectively.

The initial conditions for the kinetic equations are:

$t=0, C_{B}=C_{B 0}, C_{C}=C_{G}=C_{T}=0$

The reaction rate coefficient is "exponential" with temperature which renders the equation (4) non-linear and difficult to solve analytically, however, a linearized form expanded about the reactor temperature using Taylor's series results in significant simplification. The utilization of this expansion is justified since the rate drops so rapidly with temperature.

$$
k_{i}=A e^{-\frac{E_{i}}{R_{g} T_{o}}}\left(1+\frac{E}{R_{g} T_{o}^{2}}\left(T-T_{o}\right)\right)
$$

\section{Analytical Solutions and Simulations}

The present paper focuses only on the cylindrical shaped particle.

$$
\rho c_{p} \frac{\partial T}{\partial t}=K\left\{\frac{\partial^{2} T}{\partial r^{2}}+\frac{1}{r} \frac{\partial T}{\partial r}\right\}-Q k_{i}\left(\rho-\rho_{\infty}\right)
$$

On substituting equation 4 into equation 5 , we have:

$$
\begin{aligned}
& \rho c_{p} \frac{\partial T}{\partial t}=K\left\{\frac{\partial^{2} T}{\partial r^{2}}+\frac{1}{r} \frac{\partial T}{\partial r}\right\}- \\
& Q\left\{A e^{\frac{-E}{R T_{o}}}\left(1+\frac{E}{R_{g} T_{o}^{2}}\left(T-T_{o}\right)\right)\left(\rho-\rho_{\infty}\right)\right\}
\end{aligned}
$$

The initial and the boundary conditions are:

$$
t=0, T=T_{o}
$$

$t>0,\left(\frac{\partial T}{\partial r}\right)_{r=0}=0$

$t>0,-K\left(\frac{\partial T}{\partial r}\right)_{r=R}=h\left(T_{f}-T\right)+\sigma \in\left(T_{f}^{4}-T^{4}\right)$

Using the following dimensionless parameter to transform the equations, the initial and the boundary conditions to non-dimensionless form:

$$
\begin{aligned}
& \theta=\frac{T-T_{0}}{T_{f}-T_{0}}, \tau=\frac{K t}{\rho c_{p} R^{2}}, \alpha=\frac{Q \rho A R^{2} e^{-E / R_{g} T_{o}}}{K\left(T_{f}-T_{0}\right)}, \\
& R=\frac{r}{R^{\prime}}, \quad \gamma=\frac{E\left(T_{f}-T_{o}\right)}{R_{g} T_{o}^{2}}
\end{aligned}
$$

The heat conduction equation becomes:

$$
\frac{\partial \theta}{\partial \tau}=\frac{\partial^{2} \theta}{\partial R^{2}}+\frac{1}{R} \frac{\partial \theta}{\partial R}-\alpha(1+\gamma \theta)
$$

And the initial and boundary conditions are:

$$
\begin{aligned}
& \tau=0, \theta(R, 0)=0 \\
& \tau>0, R=0, \frac{\partial \theta}{\partial R}=0 \\
& \tau>0, R=1, \frac{\partial \theta}{\partial R}=-B i_{m} \theta
\end{aligned}
$$

where,

$$
B i_{m}=\frac{R^{\prime}}{K}\left[h+\sigma \varepsilon\left(T^{3}+T_{f} T^{2}+T_{f}^{2} T+T_{f}^{3}\right]\right.
$$


On using Laplace and Hankel transforms for the above equation, we have:

$\theta=2\left\{\left[\left[\sum_{n}\left[n \frac{\left\{\left(\alpha J_{1}(n)+n\left(n^{2}+\alpha \gamma\right)\right\}\right.}{\left(n^{2}+\alpha \gamma\right)\left(B i_{m}+n^{2}\right)}\left\{\frac{J_{0}(n \gamma)}{J_{0}^{2}(n)}\right\}\left\{\exp -\left(n^{2}+\alpha \gamma\right) \tau\right\}\right]\right]-\sum_{n}\left[\frac{n\left\{\alpha J_{1}(n)\right\} J_{0}(n \gamma)}{\left(n^{2}+\alpha \gamma\right)\left(B i_{m}^{2}+n^{2}\right) J_{0}^{2}(n)}\right]\right]\right\}$

where $\mathrm{n}$ are the roots of:

$J_{0}(n)\left[\frac{\partial \theta}{\partial R}\right]_{R=1}+J_{0}(n) B i_{m}[\theta]_{R=1}=0$

where $J_{0}(n), J_{0}(n \gamma)$ and $J_{1}(n)$ are the Bessel Functions of first kind and are given by:

$$
J_{0}(n)=\sum_{m=0}^{\infty} \frac{(-1)^{m} n^{2 m}}{2^{2 m} m ! \Gamma(m+1)} \quad J_{0}(n \gamma)=\sum_{m=0}^{\infty} \frac{(-1)^{m}(n \gamma)^{2 m}}{2^{2 m} m ! \Gamma(m+1)} \quad J_{1}(n)=\sum_{m=0}^{\infty} \frac{(-1)^{m} n^{2 m}}{2^{2 m} m ! \Gamma(m+2)}
$$

On solving the kinetic equation using Laplace transform, we arrived at:

$$
\begin{aligned}
C_{B}= & C_{B o} \exp \left\{-\left(k_{1}+k_{2}+k_{3}\right) t\right\} \\
C_{T}= & \frac{C_{B o} k_{2}}{\left\{\varepsilon\left(k_{4}+k_{5}\right)-\left(k_{1}+k_{2}+k_{3}\right)\right\}}\left[\exp \left\{-\left(k_{1}+k_{2}+k_{3}\right) t\right\}-\exp \left\{-\varepsilon\left(k_{4}+k_{5}\right) t\right]\right. \\
C_{C}= & \frac{C_{B o} k_{3}}{\left(k_{1}+k_{2}+k_{3}\right)}\left[1-\exp \left\{-\left(k_{1}+k_{2}+k_{3}\right) t\right\}\right] \\
& -\frac{\varepsilon C_{B o} k_{2} k_{5}}{\left\{\varepsilon\left(k_{4}+k_{5}\right)-\left(k_{1}+k_{2}+k_{3}\right)\right\}}\left[\frac{1}{\left(k_{1}+k_{2}+k_{3}\right)}\left[1-\exp \left\{-\left(k_{1}+k_{2}+k_{3}\right) t\right\}\right]+\frac{1}{\varepsilon\left(k_{4}+k_{5}\right)}\left[1-\exp \left\{-\varepsilon\left(k_{4}+k_{5}\right) t\right\}\right]\right. \\
C_{G}= & \frac{C_{B o} k_{1}}{\left(k_{1}+k_{2}+k_{3}\right)}\left[1-\exp \left\{-\left(k_{1}+k_{2}+k_{3}\right) t\right\}\right] \\
& -\frac{\varepsilon C_{B o} k_{2} k_{4}}{\left\{\varepsilon\left(k_{4}+k_{5}\right)-\left(k_{1}+k_{2}+k_{3}\right)\right\}}\left[\frac{1}{\left(k_{1}+k_{2}+k_{3}\right)}\left[1-\exp \left\{-\left(k_{1}+k_{2}+k_{3}\right) t\right\}\right]+\frac{1}{\varepsilon\left(k_{4}+k_{5}\right)}\left[1-\exp \left\{-\varepsilon\left(k_{4}+k_{5}\right) t\right\}\right]\right.
\end{aligned}
$$

Tabel 1

Values of the parameters employed in this study

\begin{tabular}{lllll}
\hline S/N & Parameter Description & Symbol & Value used & Source \\
\hline 1 & Bulk density of wood & $\rho$ & $650 \mathrm{Kg} / \mathrm{m}^{3}$ & Babu and Chaurasia (2003) \\
2 & Thermal conductivity of wood & $\mathrm{K}$ & $0.1256 \mathrm{~W} / \mathrm{mK}$ & Pyle and Zaror(1984) \\
3 & Initial thermal diffusivity of wood & $\alpha$ & $1.79 \times 10^{7} \mathrm{~m}^{2} / \mathrm{s}$ & Jalan and Srivastava(1999) \\
4 & Initial temperature of wood & $\mathrm{T}_{\mathrm{o}}$ & $303 \mathrm{~K}$ & Pyle and Zaror(1984) \\
5 & Radius of the particle & $\mathrm{R}$ & $0.003 \mathrm{~m}$ & Babu and Chaurasia (2003) \\
6 & Convective heat transfer co-efficient & $\mathrm{h}$ & $8.4 \mathrm{~W} / \mathrm{m}^{2} \mathrm{k}$ & Pyle and Zaror(1984) \\
7 & Reactor final temperature & $\mathrm{T}_{\mathrm{f}}$ & $643 \mathrm{~K}$ & Babu and Chaurasia(2003) \\
8 & Porosity of the wood particle & $\varepsilon$ & 0.4 & Yao Bin et al. (2006) \\
9 & Apparent activation energy & $\mathrm{A}$ & $3000 / \mathrm{s}$ & Pyle and Zaror (1984) \\
11 & Biot modified number & $\mathrm{Bi}$ & $0.82-1.22$ & - \\
12 & Specific heat capacity of wood & $\mathrm{C}_{\mathrm{p}}$ & $1670 \mathrm{~J} / \mathrm{KgK}$ & Pyle and Zaror (1984) \\
13 & Emissivity of wood & $\epsilon$ & 0.95 & Pyle and Zaror (1984) \\
14 & Stefan-Boltzmann constant & $\sigma$ & $5.67 \mathrm{x} 10^{8} \mathrm{~W} / \mathrm{m}^{2} \mathrm{~K}^{4}$ & Holman (2002) \\
15 & Heat of reaction & $\mathrm{Q}$ & $-210000 \mathrm{~J} / \mathrm{Kg}$ & Pyle and Zaror (1984) \\
16 & Wood concentration & $\mathrm{C}$ & $650 \mathrm{Kg} / \mathrm{m}^{3}$ & Babu and Chaurasia (2003) \\
17 & Tar, Gas and Char initial concentration & $\mathrm{C}_{\mathrm{T}}, \mathrm{C}_{\mathrm{G}}, \mathrm{C}_{\mathrm{C}}$ & $0 \mathrm{Kg} / \mathrm{m}^{3}$ & Babu and Chaurasia (2003) \\
\hline
\end{tabular}


Tabel 2

Kinetic constants used in the simulations

\begin{tabular}{|c|c|c|c|c|}
\hline $\mathbf{i}$ & Reaction & $A_{i}\left(s^{-1}\right)$ & $E_{i}(\mathrm{~kJ} / \mathrm{mol})$ & Sources \\
\hline 1 & Biomass $\rightarrow$ Gas & $1.3 \times 10^{8}$ & 140 & Chan(1985) \\
\hline 2 & Biomass $\rightarrow$ Tar & $2.0 \times 10^{8}$ & 133 & Chan(1985) \\
\hline 3 & Biomass $\rightarrow$ Char & $1.08 \times 10^{7}$ & 121 & Chan(1985) \\
\hline 4 & Tar $\rightarrow$ Gas & $4.28 \times 10^{6}$ & 107 & $\begin{array}{l}\text { Liden } \text { et } \\
\text { al.(1988) }\end{array}$ \\
\hline 5 & Tar $\rightarrow$ Char & $1.0 \times 10^{6}$ & 107 & $\begin{array}{l}\text { Liden } \text { et } \\
\text { al.(1988) }\end{array}$ \\
\hline
\end{tabular}

Table 1 and Table 2 show the parameters used for the simulations of the Kinetic and Heat transfer during the slow pyrolysis of wood.

\section{Results and Discussion}

Fig. $2 \mathrm{a}$ and $2 \mathrm{~b}$ show the biomass concentration variation with time and temperature respectively, as predicted from the developed model in this study. From the figures, it could be deduced that as heat is transferred to the biomass particle surface from gaseous surrounding by radiation and convection, the temperature inside the particles increases as the heat penetrates more into the interiors of the solid causing moisture evaporation i.e. drying off the moisture and the occurrence of pre-pyrolysis and main pyrolysis reactions, as discussed by Babu and Chaurasia (2003). The rate at which the biomass dries depends upon the temperature, velocity, and moisture content of the drying gas, as well as the external surface area of the feed material, the internal diffusivity of moisture, the nature of bonding of moisture to that material, and the radiative heat transfer. During the drying process/prepyrolysis process, the biomass decomposition has not commenced as depicted by a constant biomass concentration line of zero value from $(0-120$ s and 303$473 \mathrm{~K})$ the figures.

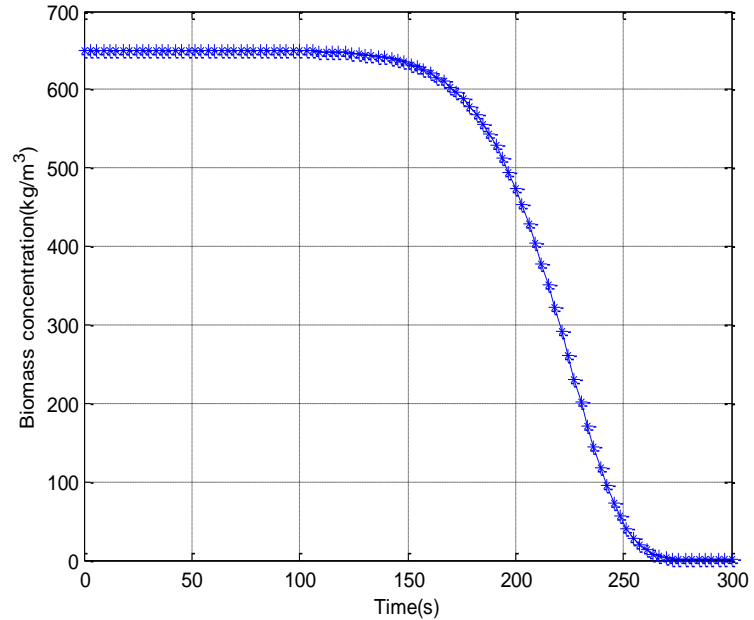

(a)

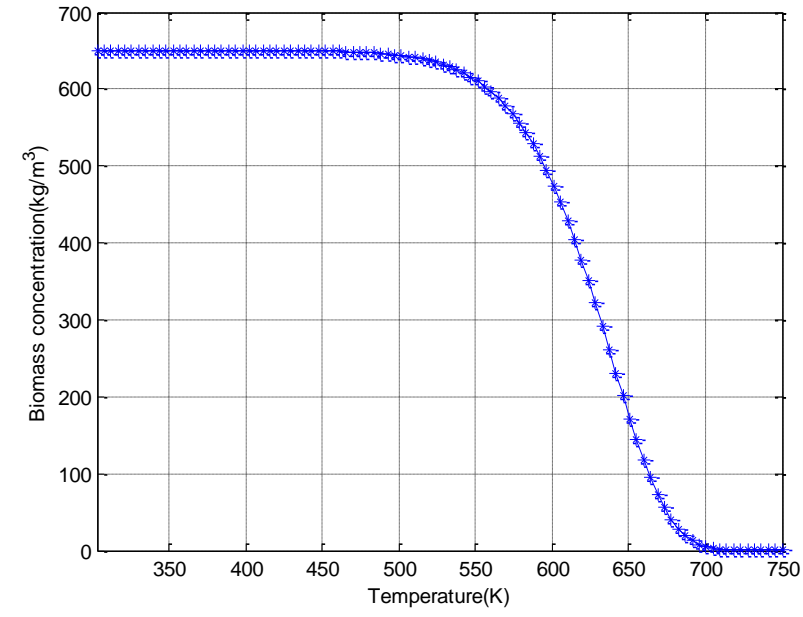

(b)

Fig. 2 Concentration history during pyrolysis of biomass (a); Variation of Concentration with temperature during pyrolysis of biomass (b)

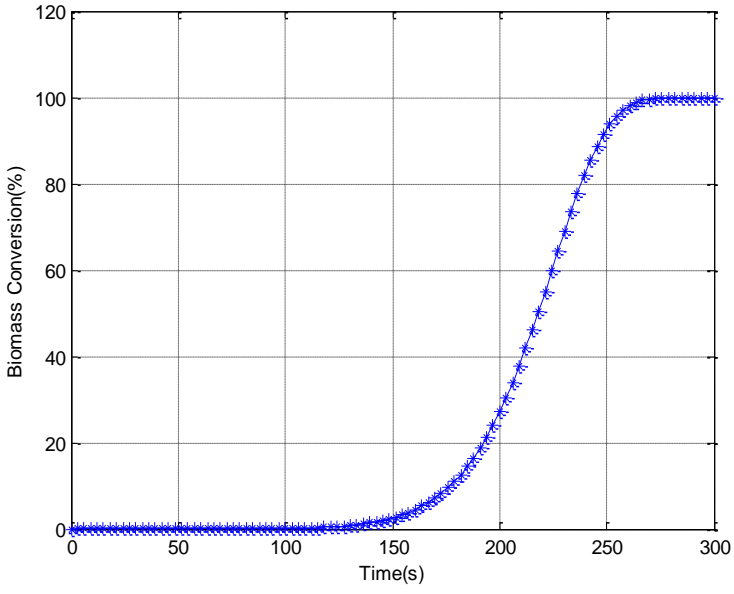

(a)

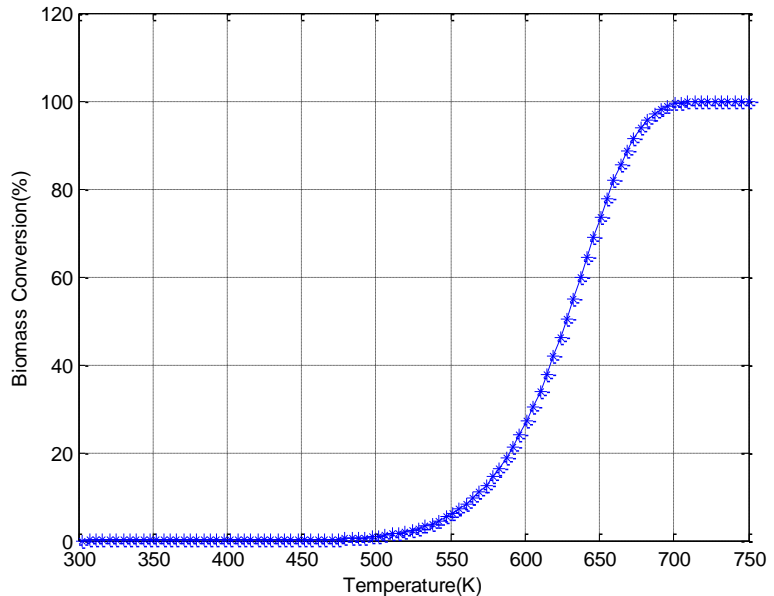

(b)

Fig. 3 Biomass history during wood pyrolysis (a); Biomass versus temperature during pyrolysis of biomass (b) 
As the temperature increases above $473 \mathrm{~K}$, biomass particle begins to decompose into char, tar and gaseous products until it reaches a temperature $723 \mathrm{~K}$ which is after $225 \mathrm{~s}$ of heating. This validates the values given in literatures that the pyrolysis of wood commences at about $200^{\circ} \mathrm{C}(473 \mathrm{~K})$ and lasts till $450-500^{\circ} \mathrm{C}$ (723$773 \mathrm{~K}$ ), depending on the species of wood. The amounts of each of the products from the thermal decomposition vary depending on the zone temperature, rate of heating, structure, and composition and size of catalysts.

Fig. $3 \mathrm{a}$ and $3 \mathrm{~b}$ depict the percentage conversion of the biomass (wood) as functions of time and temperature respectively. As it can be seen from Fig. 3 that as temperature increases starting from initial temperature of $30^{\circ} \mathrm{C}$, moisture content in the wood first evaporates and there is no conversion in the wood until the temperature reaches $473 \mathrm{~K}$ as shown in the figure. The figure shows that $100 \%$ wood conversion/pyrolysis would have been achieved i.e. the wood have been totally converted to its pyrolysis products at temperature of $723 \mathrm{~K}$.

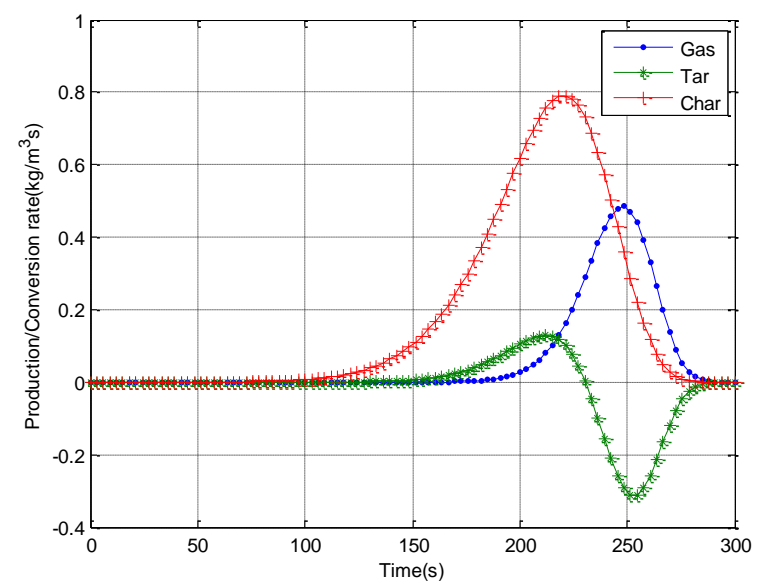

Fig. 4 compared the production and conversion rates of the pyrolytic products as functions of time and temperature respectively. The zero rate of production and conversion of the products from $0-120$ s and 303$473 \mathrm{~K}$ validate the fact that pyrolysis process actually commenced at about $473 \mathrm{~K}$. It is surprising to see that the production rate of char (the solid phase of the pyrolytic products) is higher than that of tar and gas. This may be due to the increase in the resistance for mass and heat transfers offered by the thick layer of the dried biomass i.e. for the gas and tar to evolve from the particle, they have to travel through a dried layer of the biomass which in consequence, comparably reduces their production rates. Also from the figures, it is shown that the rate of char production increases gradually from $473 \mathrm{~K}$ to about $500 \mathrm{~K}$, as the temperature increases, gases and tar evolve from the biomass and consequently, the rate of char production increases rapidly between $500-633 \mathrm{~K}$, After which there is decrease in the production rate of char till the whole wood has been converted at $723 \mathrm{~K}$.

Fig. 4 Comparison of production / conversion rates of pyrolytic products of cylindrical particle during pyrolysis of wood
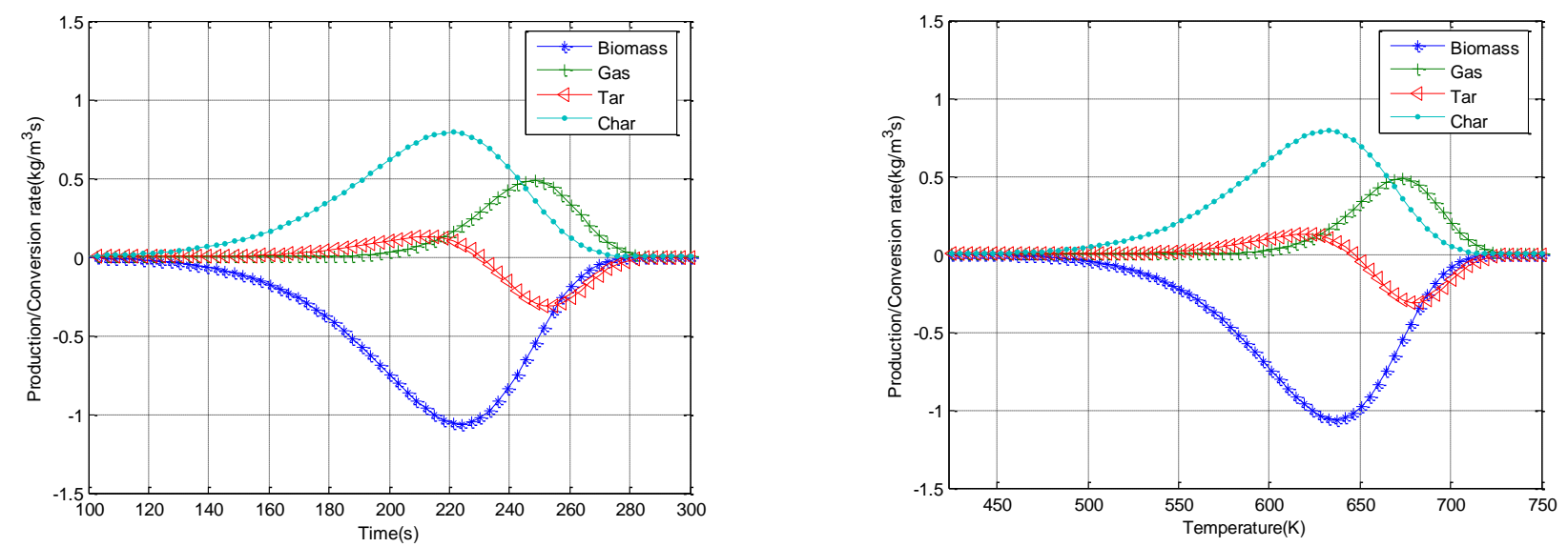

Fig. 5 Comparison of the Biomass conversion with Production/Conversion rates of the products of cylindrical particle during pyrolysis of wood 
This shows that pyrolysis process slows down from $633-723 \mathrm{~K}$ and the process finished after $225 \mathrm{~s}$ of conversion. Judging from the kinetic model, the primary pyrolysis rate of tar production starts gradually from about $525 \mathrm{~K}$ till $550 \mathrm{~K}$ and then increases rapid from $550 \mathrm{~K}$ to about $623 \mathrm{~K}$. The rate of tar production decreases rapidly from 623 to $640 \mathrm{~K}$. The secondary pyrolysis of the biomass which involves the conversion of tar to gases and char actually starts from about $640 \mathrm{~K}$ as shown in the figure. The extension of the ratetemperature figure to the negative portion of the graph depicts the conversion rate of tar to char and gas. From the figure, as the production rate of gas and char from the primary pyrolysis decreases rapidly, there is a rapid increase in the production rate of char and gas from the secondary pyrolysis reaction rate of tar conversion from $643 \mathrm{~K}$ until it reaches a peak conversion rate at $673 \mathrm{~K}$. The conversion rate of tar then rapidly decreases from the peak rate of conversion. The production and the conversion rates of all the pyrolytic products reaches zero at about $723 \mathrm{~K}$. This shows that the pyrolysis of the wood used in this investigation stops at $723 \mathrm{~K}\left(450^{\circ} \mathrm{C}\right)$.

Fig. 5 compared the production and conversion rates of the pyrolytic products of biomass with the conversion rate of biomass as functions of time and temperature respectively. From the figures, it could be deduced that the at any time and temperature, the production and conversion rates of the pyrolytic products of biomass is equal to the conversion rate of the biomass and the biomass reaches its peak conversion rate of $1.1 \mathrm{~kg} / \mathrm{m}^{3} \mathrm{~s}$ at about $640 \mathrm{~K}$. After which the rate of the pyrolysis process decreases rapidly until the conversion is completed at $723 \mathrm{~K}$.

Fig. 6 demonstrated the concentration histories and profiles of biomass and its products during the pyrolysis of biomass. As it is shown in the figures that concentration of char increases rapidly from $473 \mathrm{~K}$ till about $673 \mathrm{~K}$, and thereafter, it continue to fall. This might be due to the fact that the combustion / gasification of char in the zone below the pyrolysis zone has commenced at this temperature and the reaction of char with oxygen or other gases in these zones consequently reduces the amount/concentration of char in the pyrolysis zone. Also the reactions at this temperature between char and other gases result in gases generation and thereby causing an increase in the production of gases at the pyrolysis zone since the processes (drying, pyrolysis, combustion and gasification) involved in the thermochemical conversion of biomass occur simultaneous at some overlapping temperatures. From the figure it could be deduced that at temperature $643 \mathrm{~K}$ which signifies the end of primary pyrolysis, the tar concentration started to reduce rapidly. This is because the secondary pyrolysis which involves the conversion of tar to gases and char commences at this temperature. At temperature of $723 \mathrm{~K}$, which the end of the pyrolysis process, the whole concentration of the biomass has been converted to char and tar in equal proportion.

Figure 7 shows results of the analytical solution of the dimensionless particle temperature histories and profiles. The results show the effects of the modified Biot number on the temperature histories and profiles. From the results, as the modified Biot number decreases, the temperature history at the center of the particle increases. This shows that the temperature history and profile seems to be favoured at values of Biot number that is less than 1 since more heat is needed to be conducted within the particle to enhance the pyrolysis of the biomass particle than the heat being convected and radiated to the particle surface.
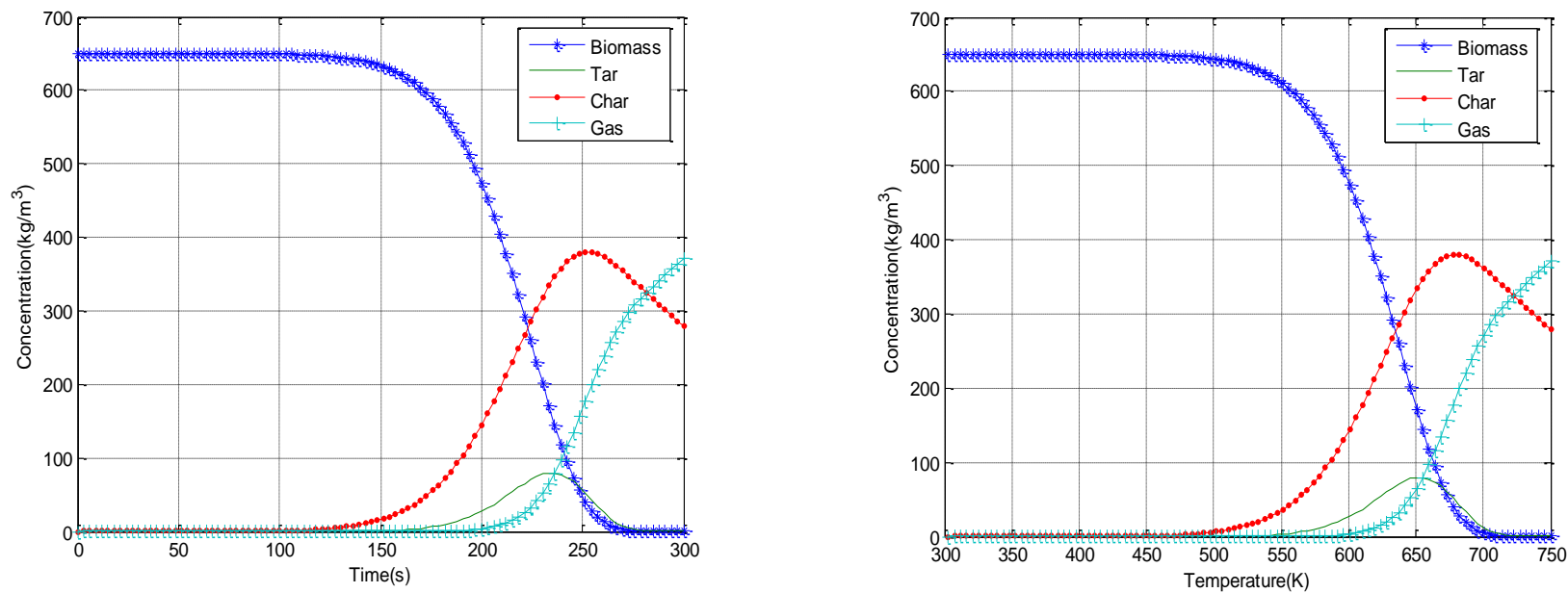

Fig. 6 Comparison of the Biomass concentration with Production/concentration of the products of during pyrolysis of wood 

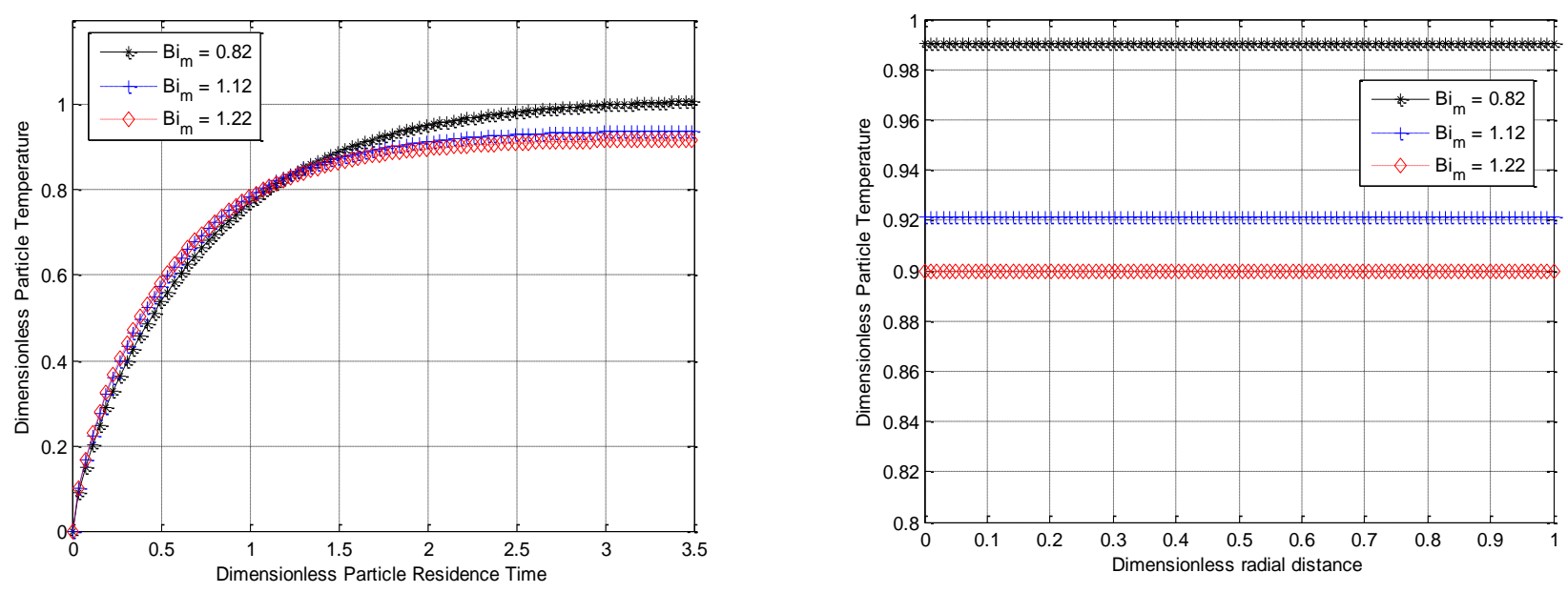

Fig. 7 Particle temperature as a function of time and at the centre of the cylindrical pellet of $\operatorname{radius}\left(\mathrm{R}=0.003 \mathrm{~m}, \mathrm{~T}_{\mathrm{o}}=303 \mathrm{~K}, \mathrm{~T}_{\mathrm{f}}=643 \mathrm{~K}, \mathrm{r}=0\right)$

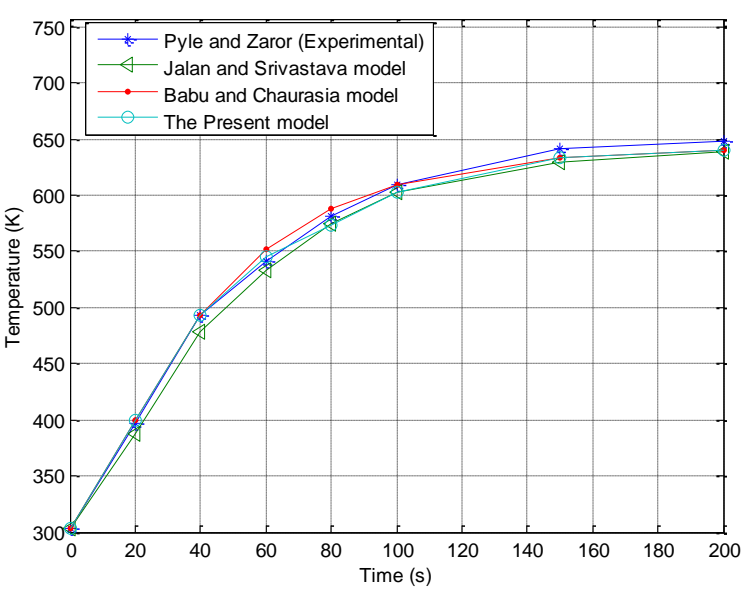

(a)

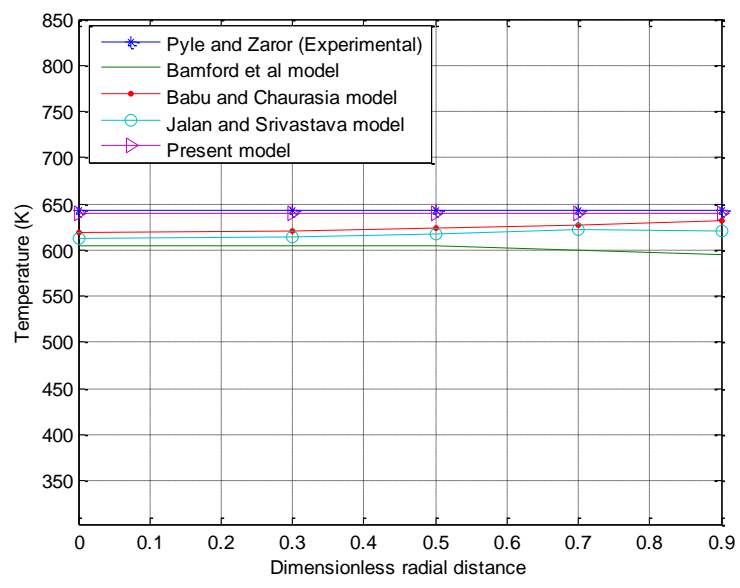

(b)

Fig. 8 Comparison of the heat transfer models results with the previous work

Fig. 8a and $\mathrm{b}$ shows the temperature profile as a function of time at the centre (i.e. $r=0$ ) of the cylindrical pellet of radius $0.003 \mathrm{~m}$. This is compared with the experimental data obtained by Pyle and Zaror (1984), the profiles obtained through numerical solutions by Bamford et al. (1946), Jalan and Srivastavaand (1999), Crank and Malan (1988), Babu and Chaurasia (2003) at the centre of the cylindrical pellet. It could be seen from the figures that as the Biot number decrease, the model become an increasingly good predictor. The model is adequate at Bim less than 1 which shows almost indistinguishable results from the experimental results of Pyle and Zaror. The region of the validity of the model is defined by the value of Biot number that is less than 1. It is found that the models developed in the present study are in excellent agreement with the experimental data and in the region of validity it presents better results in agreement with the experimental results than the other developed model as it shown in table 3 . It is found from Table 2 that the average percentage error and standard deviation from experimental data are significantly less in the prediction of the present model as compared to the predictions of the Jalan and Srivastava model and model of Babu and Chaurasia. The results discussed above have a lot of practical importance and physical significance in industrial pyrolysis applications. The results are also important and useful for the design of biomass gasifiers, reactors etc. The findings of the work are also relevant to the question of reactor design since it shows that simple heat transfer models of primary pyrolysis are generally adequate and that, in some circumstances, very simple models will serve.

Table 3 depicts the comparison of Results. From the Table, using the Experimental results of Pyle and Zaror (1984) as the reference point, it shown that the present analytical model has lower percentage error and standard deviation than the other previously numerical models developed be Jalan and Srivasta (1999) and Babu and Chaurasia (2003). 
Tabel 3

Comparison of results

\begin{tabular}{ccccc}
\hline \multicolumn{5}{c}{ Temperature } \\
\hline Time & $\begin{array}{c}\text { Pyle and } \\
\text { Zanor } \\
\text { (Exp) }\end{array}$ & $\begin{array}{c}\text { Jalan and } \\
\text { Srivasta's } \\
\text { model }\end{array}$ & $\begin{array}{c}\text { Babu and } \\
\text { Chaurasia's } \\
\text { model }\end{array}$ & $\begin{array}{c}\text { The } \\
\text { Present } \\
\text { model }\end{array}$ \\
\hline 0 & 303 & 303 & 303 & 303 \\
20 & 397 & 387 & 400 & 400 \\
40 & 493 & 478 & 493 & 493 \\
60 & 541 & 533 & 552 & 545 \\
80 & 581 & 574 & 588 & 573 \\
100 & 609 & 602 & 610 & 602 \\
150 & 641 & 630 & 634 & 633 \\
200 & 648 & 639 & 640 & 640 \\
Ep & & 1.56 & 0.75 & 0.439 \\
Sd & & 0.0189 & 0.0106 & 0.0103 \\
\hline
\end{tabular}

\section{Conclusion}

In this work, the analytical solutions of kinetic and heat transfer during the pyrolysis of a single biomass particle has been developed. The developed models through the analytical solutions were used to investigate the kinetics of the particle pyrolysis, the effects of heat of reaction, convective and radiative heat transfer on the pyrolysis of a biomass particle. The results from the proposed analytical models are in good agreement with the reported experimental results. The average percentage error and standard deviation from experimental data are significantly less in the prediction of the analytical model when compared to the predictions of the previous models. This work is of great importance in the design of some pyrolysis reactors/units and in the optimal design of the biomass gasifiers.

\section{Nomenclature}

$A 1 ; A 2 ; A 3 ; A 4 ; A 5$ frequency factor, $1 / \mathrm{s}$

$\mathrm{Bi}_{\mathrm{m}}$ Modified Biot number

C concentration, $\mathrm{kg} / \mathrm{m}^{3}$

$\mathrm{C}_{\mathrm{p}}$ specific heat capacity, $\mathrm{J} / \mathrm{kgK}$

$\mathrm{E}$ activation energy, $\mathrm{J} / \mathrm{mol}$

$\mathrm{h}$ convective heat transfer coefficient, $\mathrm{W} / \mathrm{m}^{2} \mathrm{~K}$

$\mathrm{K}$ thermal conductivity, $\mathrm{W} / \mathrm{mK}$

$k_{1} ; k_{2} ; k_{3} ; k_{4} ; k_{5}$ rate constants, $1 / \mathrm{s}$

$\mathrm{Q}$ heat of pyrolysis, J/Kg

$r$ radial distance, $m$

$\mathrm{R}$ radius for cylindrical particle, $\mathrm{m}$

$\mathrm{R}_{\mathrm{g}}$ universal gas constant, $\mathrm{J} / \mathrm{mol}$

$\mathrm{t}$ time, $\mathrm{s}$

$\mathrm{T}_{\mathrm{f}}$ reactor final temperature, $\mathrm{K}$

$\mathrm{T}$ temperature, $\mathrm{K}$

$\mathrm{R}^{\prime}$ dimensionless radial distance

\section{Greek letters}

$\rho$ Bulk density of wood, $\mathrm{Kg} / \mathrm{m}^{3}$

$\rho$ Ultimate density of wood, $\mathrm{Kg} / \mathrm{m}^{3}$

$\tau$ dimensionless time $\theta$ dimensionless temperature

$\epsilon$ emissivity coefficient

$\varepsilon$ void fraction of particle

$\sigma$ Stefan Boltzmann constant, $\mathrm{W} / \mathrm{m}^{2} \mathrm{~K}^{4}$

$\alpha$ Heat of reaction number

\section{Subscripts}

B virgin biomass

G gases

C char

$\mathrm{T}$ tar

$\mathrm{G}$ gas

0 initial

f final

\section{References}

Babu B.V. \& Sheth P.N. (2006) Modeling and simulation of reduction zone of downdraft biomass gasifier: effect of char reactivity factor. Energy Conversion and Management, 47 2602-2611.

Babu, B.V. \& Chaurasia, A.S. (2003) Modeling for pyrolysis of solid particle: kinetics and heat transfer effects. Energy Conversion and Management, 44, 2251-2275.

Babu, B.V. \& Chaurasia, A.S. (2004) Pyrolysis of biomass: improved models for simultaneous kinetics and transport of heat, mass and momentum Energy Conversion and Management, 45, 1297-1327.

Bamford, C.H., Crank, J. \& Malan, D.H., (1946) The combustion of wood. Part I. Proceedings of the Cambridge Philosophical Society, 42, 166-182.

Bruch C.B. \& Nussbaumer, P.T. ( 2003) Modelling wood combustion under fixed bed conditions, Fuel, 82, 729-738.

Chan, W.R., Kelbon, M. \& Krieger, B.B. (1985) Modeling and experimental verification of physical and chemical processes during pyrolysis of large biomass particle. Fuel, 64, 1505-1513.

Di Blasi, C. ( 1993) Analysis of convection and secondary reaction effects within porous solid fuels undergoing pyrolysis. Combustion Science and Technology, 90, 315-340.

Fan, L.T., Fan, L.S., Miyanami, K., Chen, T.Y. \& Walawender, W.P. (1977) A mathematical model for pyrolysis of a solid particleeffects of the Lewis number. The Canadian Journal of Chemical Engineering, 55, 47-53.

Font, R., Marcilla, A., Verdu, E. \& Devesa, J. (1990). Kinetics of the pyrolysis of almondshells andalmondshells impregnatedwith $\mathrm{CoCl} 2$ in a Fluidized bed reactor and in a Pyroprobe 100. Industrial and Engineering Chemistry Research, 29, 1846-1855.

International Energy Agency (2012) World energy Outlook. available: http://www.iea.org

IPCC (1996) Intergovernmental Panel on Climate Change, Chapter 19: "Energy Supply Mitigation Options" in Impacts, Adaptations and Mitigation of Climate Change: Scientific-Technical Analyses. Contribution of Working Group II to the Second Assessment Report of the Intergovernmental Panel on Climate Change.

Jalan, R.K. \& Srivastava, V.K. (1999) Studies on pyrolysis of a single biomass cylindrical pellet-kinetic and heat transfer effects. Energy Conversion and Management, 40, 467-494.

Kansa, E.J., Perlee, H.E. \& Chaiken, R.F. (1977) Mathematical model of wood pyrolysis including internal forced convection. Combustion and Flame, 29, 311-324.

Kanury, A.M. \& Blackshear, P.L. (1970) Some considerations pertaining to the problem of wood-burning. Combustion Science and Technology, 1, 339.

Koufopanos, C.A., Papayannakos, N., Maschio, G. \& Lucchesi, A. (1991) Modelling of the pyrolysis of biomass particles. Studies on kinetics, thermal andheat transfer efects. The Canadian Journal of Chemical Engineering, 69, 907-915.

Kung, H.C. (1972) A mathematical model of wood pyrolysis. Combustion and Flame, 18, 185-195.

Lee, C.K., Chaiken, R.F. \& Singer, J.M., (1976) Charring pyrolysis of wood in 0res by laser simulation. In: Proceedings of the 16th Symposium (International) on Combustion. The Combustion Institute: Pittsburgh, 1459-1470. 
Mandl C., Obernberger I. \& Biedermann F., (2009) Updraft fixed-bed gasification of softwood pellets: mathematical modelling and comparison with experimental data In: proceedings of the 17 European Biomass Conference \& Exhibition Hamburg, Italy.

Matsumoto, T., Fujiwara, T. \& Kondo, J. (1969) Nonsteady thermal decomposition of plastics. $12^{\text {th }}$ International Symposium on Combustion , 515-524

Melaaen, M.C. \& Gronli M.G., (1997) Modeling and simulation of moist wood drying and pyrolysis. In: Bridgwater, A.V., Boocock, D.B.G. (Eds.), Developments in Thermochemical Biomass Conversion. Blackie, London, pp. 132-146.

Miyanami, K., Fan, L.S., Fan, L.T. \& Walawender, W.P. (1977) A mathematical model for pyrolysis of a solid particle-effects of the heat of reaction. The Canadian Journal of Chemical Engineering, 55, 317-325.

Pyle, D.L. \& Zaror, C.A. (1984) Heat transfer and kinetics in the low temperature pyrolysis of solids. Chemical Engineering Science, 39, 147-158.

Roberts, A.F. \& Clough, G. (1963) Thermal degradation of wood in an inert atmosphere. In: Proceedings of the ninth Symposium (International) on Combustion, The Combustion Institute, Pittsburgh, 158-167.

Shafizadeh, F. \& Chin, P.P.S. (1977) Thermal deterioration of wood. ACS Symposium Series, 43, 57-81.
Sheth P.N. \& Babu B.V. (2006) Kinetic modeling of the pyrolysis of biomass. National Conference on Environmental Conservation, Pilani, India, 453-458.

Simmons, G. M. \& Gentry, M. (1986) Particle size limitations due to heat transfer in determining pyrolysis kinetics of biomass. Journal of Analytical and Applied Pyrolysis, 10, 117-127.

Slopiecka, K., Bartocci, P. \& Fantozzi, F. (2011) Thermogravimetric analysis and Kinetic study of poplar wood pyrolysis, 3rd International Conference on Applied Energy, Perugia, Italy, 16871698.

Thurner, F. \& Mann, U. (1981) Kinetic investigation of wood pyrolysis. Industrial and Engineering Chemical Process Design and Development, 20, 482-488.

Tinney, E.R. (1965) The combustion of wood dowels in heated air. In: Proceedings of the 10th Symposium (International) on Combustion. The Combustion Institute, Pittsburgh, 925-930

Villermaux, J., Antoine, B., Lede, J. \& Soulignac, F. (1986) A new model for thermal volatilization of solid particles undergoing fast pyrolysis. Chemical Engineering Science, 41, 151-157.

Weerachanchai P., Tangsathitkulchai C. \& Tangsathitkulchai, M. (2010) Comparison of Pyrolysis Kinetic Model for Thermogravimetric analysis of Biomass. Suranree Journal of Tecnologies, 17(4), 387-400.

Yang Y. B., Phan A.N, Ryu C., Sharifi V. \& Swithenbank J. (2007) Mathematical modelling of slow pyrolysis of segregated solid wastes in a packed-bed pyrolyser. Fuel, 86 (1-2), 169-180. 